Meta

Journal des tradlucteurs

Translators' Journal

\title{
Le congrès de la SILF et la traduction
}

\section{Solange Vouvé}

Volume 28, numéro 4, décembre 1983

URI : https://id.erudit.org/iderudit/004579ar

DOI : https://doi.org/10.7202/004579ar

Aller au sommaire du numéro

Éditeur(s)

Les Presses de l'Université de Montréal

ISSN

0026-0452 (imprimé)

1492-1421 (numérique)

Découvrir la revue

Citer cette note

Vouvé, S. (1983). Le congrès de la SILF et la traduction. Meta, 28(4), 431-432.

https://doi.org/10.7202/004579ar

Ce document est protégé par la loi sur le droit d'auteur. L'utilisation des services d'Érudit (y compris la reproduction) est assujettie à sa politique d'utilisation que vous pouvez consulter en ligne.

https://apropos.erudit.org/fr/usagers/politique-dutilisation/
Cet article est diffusé et préservé par Érudit.

Érudit est un consortium interuniversitaire sans but lucratif composé de l’Université de Montréal, l'Université Laval et l'Université du Québec à Montréal. Il a pour mission la promotion et la valorisation de la recherche. https://www.erudit.org/fr/ 
Comment définir ce qui constitue un « changement " en traduction?

Ce sont les réactions à ces questions qu'ont présentées un certain nombre d'intervenants dans la première partie de la séance. Puis le rapporteur a repris, dans une synthèse magistrale, les contributions ainsi offertes. Mais il les préface en insistant encore sur le rapport entre la traduction et la communication, et sur la place du traducteur entre émetteur et récepteur. L'intervention de ce troisième larron qu'est le traducteur est envisagée sous trois de ses aspects : choix du traducteur, effets de ces choix sur le texte et possibilité d'établir des limites à ce choix. Il cite ensuite trois intervenants, D. Juhel, G. Misri et D. Nakos, qui insistent sur l'aspect "communication" de la traduction. Il indique la différence que font Akhmanova, Garvin et Juhel entre textes littéraires et non littéraires. Paul St-Pierre, lui, s'appuie beaucoup sur Prieto, qu'il cite à plusieurs reprises. Il mentionne ensuite d'autres intervenants, Kassai, Neve, Akamatsu, puis encore Misri et Akhamanova, qui se penchent sur les changements d'ordre culturel et linguistique indispensables.

Abordant le problème de l'intention, il cite les réactions de Martinet (le traducteur est au service d'autrui, de l'auteur d'abord, des lecteurs ensuite). M. Pergnier parle du " vouloir dire de l'émetteur" et $\mathbf{H}$. Walter se demande " jusqu'où peut-on aller trop loin ? "Après être revenu à Prieto et à Derrida, Paul St-Pierre cite encore la réaction de Manning, pour qui la traduction est " parfaite" "if it results in a one-toone correspondence of meaning created in the minds of the target audience in the two languages".

Passant ensuite au problème du message, il signale que c'est Julıel qui traite le plus directement du problème, en précisant qu'il faut traduire la somme globale de l'information. La plupart des spécialistes font bien la distinction entre ce qu'exigent les textes littéraires et les autres. Il cite encore S. Vouvé, pour qui "le texte en dit toujours plus " et pour qui l'intervention du traducteur est marquée par des choix qui gauchissent le discours.

Il répond finalement à sa première question sur l'approche autre que normative par l'affirmative : "Non seulement elle est possible, mais elle est nécessaire. " Quant aux deux autres questions, il y répond négativement : "Tout ce qu'on peut faire, c'est de tenter de dégager quelle a été l'approche du traducteur et de voir si elle correspond à celle qui devait être adop- 
tée à l'époque et dans la société où la traduction a été faite."

Solange Vouvé 